\title{
A Study on Effects of Dementia Prevention Program
}

\author{
Young-Sun Park ${ }^{1}$ and Young-Ju Jee ${ }^{2}$ \\ ${ }^{1}$ Department of Nursing, Kyungbok University, 154 Sinpyeong-ro Sinbuk-myeon, \\ Pocheon-si, Gyeonggi-do 11138, Korea \\ ${ }^{2}$ Department of Nursing, Kyungnam University, Woryeongbuk 16-gil Masanhappo- \\ gu, Changwon-si, Gyeongsangnam-do 631-701, Korea \\ lyspark@kyungbok.ac.kr, ${ }^{2}$ jeeyoungju@kyungnam.ac.kr
}

\begin{abstract}
This study investigated the effect of the dementia prevention program on cognitive function, emotional function, and activity of daily living. The score of MMSE-DS (MiniMental State Examination-Dementia Scale), a tool for cognitive function assessment, increased statistically significantly. The score of SGDS-K (Short form Geriatric Depression scale-Korean version), which assessed emotional function, increased though it did not reach a statistically significant level. The score of IADL (Instrumental Activity of Daily Living), a tool used to assess activities of daily living, showed a statistically non-significant decrease. These results suggest that the program presented in this study is appropriate as a dementia prevention program and it is necessary to continuously develop and expand the program as a program for the prevention of dementia of the elderly.
\end{abstract}

Keywords: Dementia, Dementia prevention, Cognitive function, Emotional function, Activity of daily living

\section{Introduction}

\subsection{The need for research}

Dementia, a brain disease, is a complex clinical syndrome that causes continuous damage to the entire brain function leading to problems related to language, comprehension, judgment, and behavior as well as memory and widely affects the personality, thinking, and judgment [1]. With family nuclearization and the increased participation of women in economic activities, the situation and responsibilities for supporting the elderly in the home are gradually weakening, and the voice calling for the responsibility of the government and society for elderly support is increasing. Nursing care for the elderly with dementia, therefore, has become a problem that is not affordable at home, and responsibility for caring for the elderly with dementia is shifting from home to community or facility [2].

As the importance of prevention and management of dementia at the national level has been emphasized, a dementia center of each local government and a regional dementia support center have been established to build a systematic and comprehensive dementia

Article history:

Received (March 27, 2019), Review Result (April 28, 2019), Accepted (May 29, 2019) 
management system [3]. These centers, which consist of experts, are responsible for the prevention of dementia and the burden of dementia families through early prevention and early screening, and early intervention for dementia patients [4]. In addition, facilities for community-living elderly and patients with dementia and a service delivery system within the community are established and health professionals are trained and released. In addition, many facilities and communities are seeking to provide quality services by supplementing the insufficient workforce by utilizing volunteers is increasing [5].

The solution to dementia, however, is not a simple problem, thus should be developed in a comprehensive and complex way and should be provided to the field to achieve satisfactory effect [6]. Cognitive function training requires an integrated program, rather than monotherapy, that stimulates various aspects, such as cognition, emotion, and exercise [7].

The purpose of this study was, therefore, to investigate the effects of the dementia prevention program on cognitive and emotional functions and activity of daily living in elderly living at home by applying the program composed of dementia education, cognition, emotion, and physical activity to them.

\subsection{Purpose of research}

The purpose of this study is to investigate the effect of the program on the cognitive function, emotional function, and daily life movement ability of the elderly by applying the dementia prevention program included in the elderly residing in the community designated as the safe town of dementia

\subsection{The hypothesis of the research}

Hypothesis 1. The subjects who received the dementia prevention program will have higher MMSE-DS scores.

Hypothesis 2. Those who receive a program to prevent dementia will have a lower GDS-K score.

Hypothesis 3. Those who receive a program to prevent dementia will have lower IADL scores.

\section{Method}

\subsection{Design and subject}

The subjects of this non-synchronized study to investigate the effects of a dementia prevention program on cognitive and emotional functions and activity of daily living were 11 elderly living at a dementia care village located in N city, Gyeonggi Province.

\subsection{Instruments}

The general characteristics of subjects such as sex, age, education level, job, marital status, type of residence, the motive of participation, and health coverage status were collected by questionnaire survey. The cognitive function was measured using the Mini-Mental State Examination for Dementia Screening (MMSE-DS) which has established normal standards for the Korean elderly and has been adjusted from the Korean Mini-Mental State Examination to lower the effects of education level on the results [8]. The emotional function of subjects was measured translated Short Geriatric Depression Scale (SGDS) developed by Sheikh and 
Yesavage as a short form (15 items) of the Geriatric Depression Scale (GDS) developed by Yesavage et al. (1983). This scale is one of the most widely used screening tools in Korea [9]. The activity of daily living function of subjects was measured using the Korean Instrumental Activities of Daily Living (K-IADL) developed by Won [10].

\subsection{Data collection}

The dementia prevention program was provided once per week for 8 weeks, once per week, from Jan. 1st to Mar. 20, 2019, at a dementia care village located in N city, Gyeonggi Province. A session takes about two hours. The data was collected pre- and post-program.

\subsection{Dementia prevention program}

The dementia prevention program provided in this study aims to educate knowledge and exercise for dementia prevention. The contents of dementia knowledge included understanding dementia patients, supporting the dementia family, early detection of dementia, prevention of dementia, exercise to prevent dementia, and making a dementia-friendly society. Dementia prevention exercises included a sheet-ball game, coking Ssuk-gae-dduck, a ribbon game, Yut game, bean bag making, and a bean bag game. The program was administered for eight weeks once per week, resulting in eight sessions [Table 1].

Table 1. Dementia prevention program

\begin{tabular}{|c|c|c|c|c|c|c|}
\hline Sess & $\begin{array}{c}\text { Pre-program } \\
\text { activities _ } \\
\text { Share story }\end{array}$ & $\begin{array}{l}\text { Dementia } \\
\text { education }\end{array}$ & Rest & $\begin{array}{c}\text { All activities by } \\
\text { topic }\end{array}$ & Theme program & closing \\
\hline & 10 minutes & 30 minutes & $\begin{array}{c}10 \\
\text { minutes }\end{array}$ & 10 minutes & 40 minutes & $\begin{array}{c}10 \\
\text { minutes }\end{array}$ \\
\hline 1 & \multirow{8}{*}{$\begin{array}{l}\text { Reply with } \\
\text { quote }\end{array}$} & Dementia partner? & \multirow{8}{*}{ Rest } & $\begin{array}{c}\text { Talae Thread } \\
\text { Winding }\end{array}$ & $\begin{array}{l}\text { Self- introduction, } \\
\text { program guide }\end{array}$ & \multirow{8}{*}{$\begin{array}{c}\text { Balloon } \\
\text { Games, } \\
\text { Singing, } \\
\text { Snack }\end{array}$} \\
\hline 2 & & $\begin{array}{c}\text { Understanding } \\
\text { Dementia Patients }\end{array}$ & & $\begin{array}{c}\text { Thread } \\
\text { Knitting }\end{array}$ & Sheet ball game & \\
\hline 3 & & $\begin{array}{l}\text { Supporting the } \\
\text { dementia family }\end{array}$ & & $\begin{array}{l}\text { Counting } \\
\text { Numbers }\end{array}$ & $\begin{array}{c}\text { Making Ssuggae } \\
\text { tteog }\end{array}$ & \\
\hline 4 & & $\begin{array}{l}\text { Method of early } \\
\text { detection of } \\
\text { dementia }\end{array}$ & & Singing & Ribbon game & \\
\hline 5 & & $\begin{array}{l}\text { Dementia } \\
\text { prevention } \\
\text { activity }\end{array}$ & & $\begin{array}{l}\text { Talae Thread } \\
\text { Winding }\end{array}$ & yuchnol-i & \\
\hline 6 & & $\begin{array}{l}\text { Dementia } \\
\text { prevention } \\
\text { movement }\end{array}$ & & $\begin{array}{l}\text { Thread } \\
\text { Knitting }\end{array}$ & $\begin{array}{c}\text { Making } \\
\text { kongjumeoni }\end{array}$ & \\
\hline 7 & & $\begin{array}{c}\text { Dementia Partner } \\
\text { Activity }\end{array}$ & & $\begin{array}{l}\text { Counting } \\
\text { Numbers }\end{array}$ & $\begin{array}{l}\text { Kongjumeoni } \\
\text { game }\end{array}$ & \\
\hline 8 & & $\begin{array}{c}\text { Creating a } \\
\text { dementia-friendly } \\
\text { society }\end{array}$ & & Singing & Graduation & \\
\hline
\end{tabular}




\subsection{Data analysis}

The collected data were analyzed using SPSS/WIN 18.0 program. The general and educational characteristics of the subjects were analyzed using descriptive statistics (real number, percentage, mean and standard deviation), and cognitive function, emotional function, and daily life performance before and after the program were compared using an independent sample t-test.

\section{Results}

\subsection{General characteristic}

Table 2. General characteristics of subjects $(\mathrm{N}=11)$

\begin{tabular}{|c|c|c|}
\hline Characteristics & Category & Frequency $(\%) \&$ Mean \\
\hline \multirow{2}{*}{ Sex } & Male & $0(0.0)$ \\
\hline & Female & $11(100.0)$ \\
\hline \multirow{4}{*}{ Age } & Under 70 & $1(9.09)$ \\
\hline & $70-79$ & $4(36.4)$ \\
\hline & $80-89$ & $4(36.4)$ \\
\hline & $90-99$ & $2(18.2)$ \\
\hline \multirow{3}{*}{ Education Level } & No education & $6(54.6)$ \\
\hline & Elementary School & $4(36.4)$ \\
\hline & Middle School & $1(9.1)$ \\
\hline \multirow{3}{*}{ Job } & Employment & $5(45.5)$ \\
\hline & Unemployment & $4(36.4)$ \\
\hline & No response & $2(18.2)$ \\
\hline \multirow{2}{*}{ Spouse } & No & $10(90.9)$ \\
\hline & Yes & $1(9.1)$ \\
\hline \multirow{2}{*}{ Health Insurance } & No & $10(90.9)$ \\
\hline & No response & $1(9.1)$ \\
\hline \multirow{2}{*}{ Cognitive Impairment } & No & 10(90.9) \\
\hline & Yes & $1(9.1)$ \\
\hline
\end{tabular}

\subsection{Effect of the Dementia Prevention Program}

The scores measured pre- and post-program were compared and the results showed that the MMSE-DS score increased statistically significantly $(\mathrm{t}=-3.35, \mathrm{p}=.007)$. The SGDS score and LADL score showed no statistically significant change, though a slight decrease was

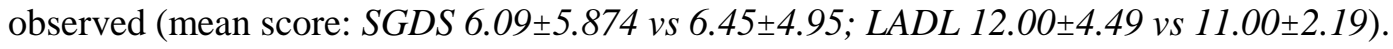


Table 3. Effects of dementia prevention program $(\mathrm{N}=11)$

\begin{tabular}{|c|c|c|c|c|c|}
\hline Parameter & Domain & $\begin{array}{c}\text { Pretest } \\
(\mathrm{M} \pm \mathrm{SD})\end{array}$ & $\begin{array}{c}\text { Posttest } \\
(\mathrm{M} \pm \mathrm{SD})\end{array}$ & $\mathrm{t}$ & $\mathrm{p}$ \\
\hline \multicolumn{2}{|c|}{ MMSE-DS } & $22.91 \pm 5.70$ & $24.36 \pm 5.61$ & -3.35 & .007 \\
\hline SGDS-K & $6.09 \pm 5.87$ & $6.45 \pm 4.95$ & -0.482 & .640 \\
\hline IADL & $12.00 \pm 4.49$ & $11.00 \pm 2.19$ & 0.680 & .512 \\
\hline
\end{tabular}

\section{Discussion}

This study was conducted to examine the effects of cognitive function, emotional function, and daily life function of the subjects after providing a dementia prevention program to the elderly over 65 years old.

The MMSE-DS score showed was a statistically significant change, indicating that the cognitive function was improved after the program. The change in IADL scores was not statistically significant, though a slightly improvement was observed. These results are similar to the results of a study on the improvement of cognitive function, physical function, and emotional function by providing a program using Korean familiarity such as childhood play, stone dressing, making songpyeon, and samgyetang to the elderly with dementia [11]. In this study, we used the subjects that we had experienced in the past, such as making ssuggae tteog, making kongjumeoni, and playing kongjumeoni. The subjects of these familiar programs were interpreted as affecting the cognitive and physical improvement of the elderly. But the SGDS-K score increased though it did not reach a statistically significant level. This deterioration of depression is a problem to be considered in future program development.

\section{Conclusion}

This study evaluated the effectiveness of a dementia prevention program for the elderly living in a dementia care village.

As a result of the study, it was shown that the dementia prevention program for elderly people aged 65 and over is effective in improving cognitive function and physical function as MMSE-DS and IADL scores increase.

The dementia prevention program proposed in this study, therefore, may be a suitable one for the elderly who, due to aging, showed decreased cognitive function and activity of daily living. However, there is a difficulty in generalizing because it is a study of elderly people living in dementia relief village 1 place. It is suggested that it is necessary to development of the program and expand the participants and do repeated research so that it can be settled as a dementia prevention program in the future.

\section{References}

[1] J. Cerejeira, L. Lagarto, and E.B. Muka etova-Ladinska, "Behavioral and psychological symptoms of dementia," Front Neurol, vol.3, no.1, pp.73, (2012)

[2] B. Cheong, "The reciprocity of intergenerational support exchange and its characteristics: Analyzing data on elders in Seoul area," Korean Association for Survey Research, vol.27, no.2, pp.503-518, (2007)

[3] S.H. Ryu, "The role of the local center for dementia in the management system of dementia in Seoul," J Korean Geriatr psychiatry, vol.11, no.1, pp.12-15, (2007) 
[4] D. Y. Lee, "Seoul dementia management project and Seoul metropolitan center for dementia," J Korean Geriatr psychiatry, vol.11, no.1, pp.8-11, (2007)

[5] S. Y. Jung and H.U. Baik, Mental Health \& Social Work, vol.21, no.12, pp.60-89, (2005)

[6] H. R. Ji, S. H. Choi, M. S. Cho, and R. A. Ju, "The effects of the continuous dementia nursing intervention program on cognitive function and depression of the elderly with mild dementia in the community," J Korean Gerontol Nurs, vol.6, no.2, pp.216-227, (2004)

[7] J. Y. Kim, S. G. Lee, and S. K. Lee, "The relationship between health behaviors, health status, activities of daily living and health-related quality of life in the elderly," Journal of the Korean Gerontological Society, vol.30, no.2, pp.471-484, (2010)

[8] T. H. Kim, J. H. Jhoo, J. H. Park, J. L. Kim, S. H. Ryu, S. W. Moon, I. H. Chon, D. W. Lee, J. C. Yoon, S. B. Lee, M. D. Kim, and K. W. Kim, Psychiatry, vol.7, no.2, pp.102-108, (2010)

[9] M. J. Cho, J. M. Bae, G. H. Suh, B. J. Hahm, J. K. Kim, D. W. Lee, and M. H. Kang, "Validation of Geriatric Depression Scale, Korean Version(GDS) in the assessment of DSM-III-R major depression," J Korean Neuropsychiatr Assoc, vol.38, pp.48-63, (1999)

[10] C. W. Won, K. Y. Yang, Y. G. Rho, S. Y. Kim, E. J. Lee, J. L. Yoon, K. H. Cho, H. C. Shin, B. R. Cho, J. R. Oh, D. K. Yoon, H. S. Lee, and Y. S. Lee, "The development of Korean Activities of Daily Living(K-ADL) and Korean Instrumental Activities of Daily Living(K-IADL) scale,” J Korean Geriatr Soc., vol.6, no.2, pp.107-120, (2002)

[11] Y. S. Park and H. G. R. Son, "Effects of intervention using Korean traditional familiarity on cognitive and physical functions among persons with dementia," J. Korean Gerontol Nurs, vol.15, no.3, pp.257-266, (2013) 